\title{
Using Translation as Reverse Engineering to Enhance Translator Competence: A Case Study
}

\author{
Rudy Sofyan ${ }^{1}$, Bahagia Tarigan ${ }^{2}$ \\ \{rudy@usu.ac.id ${ }^{1}$, bahagia1@usu.ac.id ${ }^{2}$ \} \\ Linguistics Department, Universitas Sumatera Utara, Medan, Indonesia ${ }^{1,2}$
}

\begin{abstract}
It has long been recognised that the target text (TT) fails to convey the whole meaning of the source text (ST) and that this inevitably reduces the effectiveness of translation as a medium for cross/intercultural communication. Several studies support the view that the problem is mainly caused by the translators' inadequate understanding of the ST which is, itself, a reflection of their limited communicative competence. Responding to such a problem, the aim of this paper is 1) to investigate what the translator does as (s)he translates and to propose a radical model of that as a process of reverse engineering and 2) to consider ways in which such a process can be used to enhance the translator's communicative competence. This is a descriptive case study, taking non-professional translators as the participants. The data were collected during a focus group discussion and analysed using an interactive model of data analysis. The results of the study suggest that translation as reverse engineering has a positive role in improving translator competence by focusing on the fullest possible comprehension of the ST.
\end{abstract}

Keywords: Translation, reverse engineering, translation competence, communicative competence, case study

\section{Introduction}

Human beings are, by nature, social creatures that are always engaged in communication practices, and it is true to say that we lose our identity in the absence of communication. One of the forms of communication practice is the translation, which differs from other forms of communication since it involves at least two written languages and their cultures [1]. A translator must, therefore, possess not only the bilingual competence to communicate appropriately (being both formally correct and socially acceptable) in the two languages but, in addition, translation-specific knowledge and skills which make it possible for him/her to act as a cross-cultural bilingual mediator who bridges the gap between two different languages and cultures.

Translator competence assumes bilingual competence (both linguistic and communicative) plus the ability to consciously make sense of a text in one language and reword that sense in the form of a text in another language that possesses not only an appropriate degree of semantic (literal) sense but also communicative value. The study of translator competence has led researchers to propose several criteria or sub-competencies ([2], [3], [4], [5]).

Cao [2], for example, using a minimalist approach, proposes a multi-component model that draws on the concept of proficiency in a model of language ability proposed by Bachman 
[6] who suggests the translation proficiency consists of three components or sets of variables: translational language competence, translational knowledge structure, and translation strategic competence.

Orozco and Albir [3] propose a model of six interrelated sub-competencies: communicative competence in two languages, extra-linguistic competence, transfer competence, instrumental competence, psycho-physiological competence, and strategic competence. These may be compared with the six translation sub-competencies including bilingual, extra-linguistic, knowledge about translation, instrumental, strategic, and psychophysiological sub-competencies proposed by PACTE [4] using more recent research tools and re-validations of respective sub-competencies. Considering translation as both discipline and profession, Gopferich [5] proposes three translation competencies: communicative competence in the SL and the TL, domain competence, and tools and research competence.

Communicative competence is mentioned frequently in the previous literature as the core competence in translation. Hatim and Mason [7] consider it as the competence assuring for appropriateness in translation, PACTE [4] argues that communicative competence is predominantly procedural knowledge required to communicate in two languages, and Mbotake [8] believes in the vital role of communicative competence in translation.

Given its vital role in translation, it is not surprising that several studies on communicative competence in translation have been conducted, covering the impact of communicative competence on translation performance [8] and foreign language learning [9], the specification of levels of communicative competence [10], its place in legal translation [11], and in communicative competence acquisition [12]. These valuable studies still leave the problem of how to develop communicative competence in translation using a particular technique or approach. This study seeks to fill this gap by introducing Reverse Engineering

(RE) as a technique in creating/developing/enhancing a translator's communicative competence.

$\mathrm{RE}$ is a common technique in the fields of engineering and, in particular, Computer Science, but is relatively new in the field of translation. RE consists of disassembling or analysing an object in detail in order to discover the components involved in its manufacture [13] as input to designing, manufacturing, assembling, and maintaining products and systems [14]. More comprehensively, RE refers to the process of discovering the technological principles of a mechanical application through analysis of its structure, function, and operation that involves sometimes taking something apart and analysing its workings in detail, usually intending to construct a new device or program that does the same thing without actually copying anything from the original [15]. Since Asif [16] argues that RE can be used for a variety of purposes, one of which is to reconstruct or improve documentation and translation also deals with text reconstruction or reproduction, it seems clear that RE is possibly applicable in translation. Drawing on the rationale above, this paper aims at introducing RE in translation and demonstrates how it is used in translating a text from English into Bahasa Indonesia.

\section{Translation as Reverse Engineering}

A Reverse Engineering approach to the description of translation is based on the assumption that the process consists, in the simplest terms, of reading the source text to infer 
information from it for use in the writing of the target text. More specifically, the process moves through four stages:

1. Reading: the careful, conscious deconstruction of the source text, beginning with the analysis of the physical and obvious characteristics of the text itself and then moving back and forth between it and the four layers/levels it contains: Intertextual, Intentional, Contextual, and Cultural, to

2. Problem processing: the identification of potential translation problems and a listing of possible solutions to each of them to

3. Selecting a cultural orientation e.g. choosing between creating an overt or covert translation, and

4. Writing: the synthesis/reconstruction of the initial text, in the second language, based on what the translator has understood and wishes to include in the translation.

\section{The Case Study}

This descriptive study involved two non-professional translators - both doctoral program students majoring in linguistics - as the participants in a Focus Group Discussion (FGD) and interviews facilitated by a translation lecturer at the Universitas Sumatera Utara.

The FGD was conducted over three consecutive days with the interviews on the final day and the data collected were analysed using an interactive model of data analysis.

\section{Results and Discussion}

Each of the three days of the FGD had a different focus. On the first day, the participants were given a text written in English as the source language (SL) and its translation in Bahasa Indonesia as the target language (TL).

The source text (ST) was the opening speech of the 2019 Macau Rehabilitation International Regional Conference (downloaded from https://www.rimacau2019.org/openingspeech-for-conference/). They were asked to read the ST to understand its communicative meaning. This is particularly important in developing their communicative competence because translation is not merely the context-free linguistic task of translating words or grammatical structures from the SL to the TL, but also the cultural challenge of dealing with context-sensitive texts in a situation and culture in both the SL and the TL [17]. By having such communicative competence, a translator can make the translation communicatively appropriate [7]. Understanding the ST is one of the essential steps leading to the ability to produce a communicatively appropriate TT.

Then, they were asked to read the TT which had been translated by a professional translator. While reading the TT, they were asked to search for and identify any translation problems they could find in the TT. The ability to identify translation problems depends entirely on their understanding of the ST's communicative meaning. They were asked to collect as many translation problems as possible in the TT since such problems did not only come from issues inherent in the TT itself (e.g. confused or vague structure, rare lexical items, ambiguities, typos) but also the level of their competence. In other words, careful reading might also reveal the problems they encountered in understanding the TT. This is the early 
step of applying reverse engineering (RE) in translation, where a translator identifies problems in the translated text and also in their ability to understand.

Based on the results of the first-day FGD, several problems were found: (i) specific terminology, (ii) SL interference, (iii) meaning omission and addition, and (iv) insufficient translation skill.

On the second day, the problems that had been discovered were listed and discussed to find possible solutions. The first problem (i.e. specific terminology) was mainly caused by their limited vocabulary. The specific terminology was related to the use of highly specialized vocabulary and idiomatic expressions. A generally applicable to this problem suggested by the participants was the preparation of specialized dictionaries (dictionaries containing terminologies for certain fields) and idiom dictionaries but, for the sake of practicality, they suggested the use of electronic or online dictionaries. In this case, using a dictionary is regarded as the technique or engineering that can be used by a translator in translating another text in the same genre.

The second problem (SL interference) was apparent in the use of an awkward structure that made part of the TT look like a translated text. The solution to this problem was finding a text in the TL which had similar characteristics with the TT. In this context, they had to find some texts about opening speeches originally written in Bahasa Indonesia. By using this technique, they would write the equivalence by comparing the communicative function of certain expressions in the SL with the expressions commonly used in the TL, and the sense of SL would be eliminated in the TT. For this technique, they need to have online resource management skills ([18], [19]): the ability to use certain online resources to solve certain translations problems.

The third problem (omissions and additions of ST original meanings in the TT) was apparent in their readings of the TT. Although omissions and additions are common in translation, they are normally only considered to be permissible if they do not change the original meaning of the ST. However, in the TT, they changed the original meaning of the TT as can be seen in (1) and (2).

ST : We should expect critically challenges ahead in fully realizing the spirit of the Theme

TT : Kita harus mengantisipasi tantangan kritis di masa depan dalam merealisasikan sepenuhnya semangat Tema.

ST : Let us use all our care, competence and energy for creating peace and happiness for our brothers and sisters both in our own countries and in other parts of the world.

TT : Mari kita curahkan semua perhatian, kompetensi, dan energi kita untuk menciptakan kedamaian dan kebahagiaan serta kemajuan bagi saudarasaudara kita di negara kita sendiri dan di seluruh dunia.

In (1) the TT omits the meaning of definite article "the" in the phrase "the Theme" contained in the ST. This can be explained in terms of the different structure of the SL and the TL. While articles (e.g. the, a, etc.) play an important role in the SL, they have no structural equivalent in the TL, so there is a tendency for the meaning contained in them to be omitted in bilingual speech and writing, including translations into the TL. Omitting the meaning of the article makes the meaning of "Tema" unclear or unspecified as it raises the question "Which theme? The theme? A theme? Theme (in general)?". The competent translator will always be 
alert to the presence of articles in a text in this language (and related languages) and will be able to make the meaning of the article explicit by reference to the context by adding the word "ini" ("this") by writing "Tema konferensi ini".

In (2), in contrast, the TT contains additional meanings that are neither explicit nor implicit in the ST. The addition of the word "kemajuan" in the TT (equivalent to "the advancement" in English) is simply an exaggeration that reflects the translator's interpretation of the original meaning of the ST. The ST does not convey that the spirit of the conference would bring advancement to people, it only intends to create peace and happiness. However, the translator's interpretation implies that creating peace and happiness would necessarily result in advancement.

The fourth problem (insufficient translation skills), was particularly noticeable in their inability to use the most appropriate translation technique for a specific translation problem. This matching failure leads to their difficulty in understanding several parts of the ST, particularly in understanding long ST phrases, one of which was in understanding the equivalent of the ST phrase as in (3).

ST : the 2019 Macau Rehabilitation International Regional Conference

TT : Konferensi Regional Rehabilitasi Internasional di Makau tahun 2019

During the FGD, they confirmed that they were still unable to understand the meaning of the ST phrase in (3) even after although its translation was also given to them. They were not sure whether the TT was correct. They highlighted the phrase "Rehabilitation International" which was translated using borrowing and literal techniques into "Rehabilitasi Internasional". However, they did not agree with the word order of the phrase as noun phrases in Bahasa Indonesia use the $\mathrm{Head}^{\wedge}$ Modifier pattern. For example, the phrase "gadis cantik" is composed of the Head "gadis" ("girl") and Modifier "cantik" ("beautiful"). The phrase is equivalent to "beautiful girl" in English following the pattern Modifier^Head. Therefore, they argued that the translation should be "Internasional Rehabilitasi" considering that "rehabilitation" is the Head. However, another confusing moment was coming when they wrote their translation as "Konferensi Regional Internasional Rehabilitasi". This became meaningless when their translation meant "International Regional Conference" as this term was not applicable. People held both international conferences and regional conferences, but they never held an international regional conference.

Then, the results of the FGD provided a solution to such a problem, i.e. using the right translation technique. The phrase "Rehabilitation International" in (3) was translated using a calque technique [20], applied through a literal translation of an ST phrase where the SL structure was also kept in the TT. The participants were told that calque was different from literal translation technique, in the sense that literal translation follows the TL structure, while calque does not. This solution becomes another technique that they have to record before they do their translation task. All of the solutions that have been generated during the FGD became the technique for the participants in doing their translation task: the second step in the practice of Translation as Reverse Engineering (TARE), where the translation problems that have been identified are analysed in detail to suggest techniques that can be applied in the process of constructing the translation.

On the third and final day of the FGD, the participants were given an English text belonging to the same genre as the previous text they had analysed: the opening remarks of the international conference on immigration inspection and service (downloaded from https://www.iom.int/speeches-and-talks/opening-remarks-international-conference- 
immigration-inspection-and-service). At this stage, the real practice of TARE began, i.e. to construct a target text that "does the same thing" without actually copying anything from the first ST. In the translation process, the participants are required to use all techniques that have been presented and practiced during the first two days of the FGD to develop their communicative competence and help them in translating the text into Bahasa Indonesia.

Before translating the text, the participants were asked to read the ST to expand their communicative competence in the ST, i.e. understanding the ST context, the SL culture (a form of address, greetings), the ST social function, and the shared similar characteristics with the first ST (terminology, idioms). In translating the text, their computers were connected to the internet allowing them to use online resources. There was no time limitation in completing the translation tasks, so the participants did not work under pressure.

The results of the translation were discussed in order to find out how TARE worked in creating the ST. This was conducted using interviews. The results of the interviews indicate that TARE makes the translation process easier because they are well prepared before doing their tasks. This corresponds to the findings of several previous studies reporting that many translators often get stuck in the process of translation due to their limited communicative competence ([21], [9], [22]). At first, the participants felt that the first stage was very timeconsuming but they soon began to recognise that the initial close reading - the analytic/deconstruction stage - is a necessary and valuable process since its purpose is not merely to understand the ST, but, importantly, aimed at translation problem identification. Furthermore, the implementation of TARE does not only apply to one translation task, but it can be applied in translating other similar texts. For example, the text tried out in this study is a script - a record of speech written to be read as if not being read - specifically, an opening address at a conference. This means that the approach that has been formulated in this study can be applied in translating other conference opening speeches, and, indeed, texts of all kinds.

\section{Conclusion}

In conclusion, it is important to make clear that what has been described here is just a very small case study from which it would be premature to attempt to draw valid and generally applicable conclusions. Only two participants were involved who limited themselves to addressing just one of the stages in the translation process (problem identification and solution) in part of a single text. However, the study can legitimately claim to have shown that TARE, especially when carried out collectively and in an orderly way, can be a valuable addition to activities designed to enhance translator competence and, more generally, to the creation of more efficient translation and support the argument in favour of further research and practical evaluations of its usefulness. 


\section{References}

[1] Bell RT. Translation and translating: Theory and practice. London: Longman; 1991.

[2] Cao D. On translation language competence. Babel, 1996; 42(4): 231-238.

[3] Orozco M, Albir AH. Measuring translation competence acquisition. Meta, 2002; 47(3): 375-402.

[4] PACTE. Investigating translation competence: Conceptual and methodological issues. Meta, 2005; 50(2): 609-619.

[5] Gopferich, S. Towards a model of translation competence and its acquisition: The longitudinal study of Transcomp. In: Göpferich S, Jakobsen AL, Mees IM, editors. Behind the mind: Methods, models and results in translation process research. Copenhagen: Samfundslitteratur Press; 2009. pp. 12-39.

[6] Bachman LF. What does language testing have to offer?. TESOL Quarterly, 1991; 25(4): 671-704.

[7] Hatim B, Mason, I. Discourse and the translator. London and New York: Longman; 1990.

[8] Mbotake SG. The impact of language competence on translation performance - A case study. AJSS, 2013; 4(3): 51-65.

[9] Ayvazyan N. Communicative translation in foreign-language teaching and learning. Doctoral Thesis. Tarragona: Universitat Rovira I Virgili; 2017.

[10] Sanchez CD. Proficiency guidelines to determine levels of communicative translation competence in translation training. Master's Thesis. Universidad Nacional; 2007

[11] Piecychna B. Legal translation competence in the light of translational hermeneutics. Studies in Logic, Grammar and Rhetoric, 2013; 34(47): 141-159.

[12] Damaskou E. The role of cross-linguistic influences in the multilingual communicative competence acquisition: A classroom research in the Greek Primary School based on the use of free online linguistic resources. IJI, 2014; 7(3/4): 913-924.

[13] Webster M. The Merriam-Webster dictionary. New edition. Eastbourne: Gardners Books; 2004.

[14] Raja V. Introduction to reverse engineering. In: Raja V, Fernandes, KJ, editors, Reverse engineering: An industrial perspective. London: Springer; 2008. pp. 1-10.

[15] Ethics in computing: Reverse engineering. Available at https://ethics.csc.ncsu.edu/intellectual/reverse/study.php

[16] Asif N. Reverse Engineering Methodology to Recover the Design Artifacts: A Case Study. Proceedings of the International Conference on Software Engineering Research and Practice; 23-26 June 2003, Las Vegas, Nevada, USA; 2003.

[17] Schaffner C. Translation and quality. Philadelphia: Multilingual Matters Ltd; 1998.

[18] Sofyan R, Tarigan B. Online resources management in self-corrections and translation quality. IJSBAR, 2017; 35(2): 212-224.

[19] Rosa RN, Amri Z, Zainil Y. Developing self-revision oriented translation model: Promoting human's role as a post-editor. Proceedings of the 1st International Conference on Applied Social Sciences, Business, and Humanity; 2 November 2019, Padang, West Sumatra, Indonesia. Ghent: EAI; 2020.

[20] Molina L. Albir, AH. Translation techniques revisited: A dynamic and functionalist approach. Meta, 2002; XLVII(4): 498-512.

[21] Konishi Y. Building communicative competence: An evaluation of the effectiveness of an intensive Japanese-Language program. Doctoral Dissertation. San Francisco: University of San Francisco; 2016.

[22] Rosa RN, Amri Z, Zainil Y. Translation strategies used by student translators in solving equivalence finding-related problems. ASSEHR, 2020; 411: 394-401. 